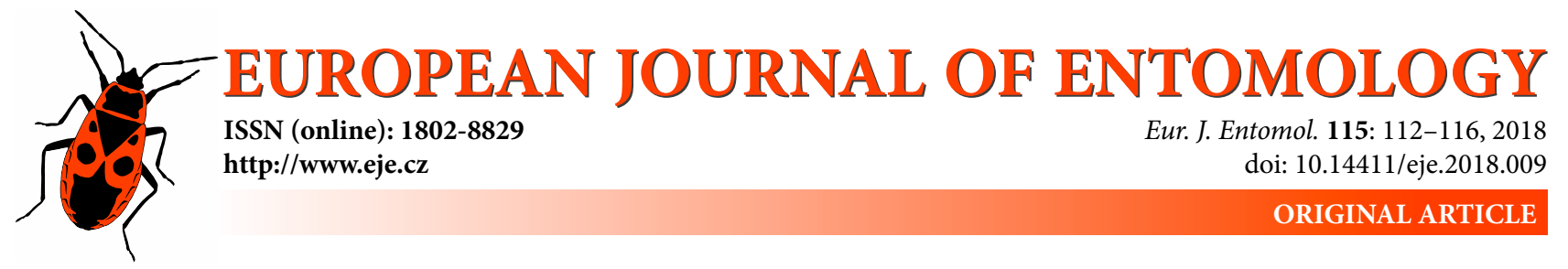

\title{
Influence of prolonged dietary experience during the larval stage on novel odour preferences in adults of noctuid stem borer moths (Lepidoptera: Noctuidae)
}

\author{
Christophe Petit ${ }^{1,2}$, Peter AhUYA ${ }^{2}$, Bruno Le RU ${ }^{1,2}$, Laure KAISER-ARnAULD ${ }^{1}$, Myriam HARRY ${ }^{1}$ \\ and PAUL-ANDRÉ CALATAYUD ${ }^{1,2}$ \\ 1 UMR EGCE (Evolution, Génome, Comportement, Ecologie), CNRS-IRD-Univ. Paris-Sud, Université Paris-Saclay, \\ Gif-sur-Yvette Cedex, France; e-mail: christophepetit86@gmail.com, bpleru@gmail.com, laure.kaiser-arnauld@egce.cnrs-gif.fr, \\ myriam.harry@u-psud.fr, paul-andre.calatayud@egce.cnrs-gif.fr \\ ${ }^{2}$ IRD c/o ICIPE, NSBB Project, P.O. Box 30772-00100, Nairobi, Kenya; e-mail: pahuya@icipe.org, pcalatayud@icipe.org
}

Key words. Lepidoptera, Noctuidae, Sesamia nonagrioides, Busseola fusca, Busseola nairobica, larval dietary experience, adult olfactory preference

\begin{abstract}
In Lepidoptera, larval dietary experience of volatile cues can induce adult preference for these cues. However, such induction may require several generations, depending in part on the degree of specialization of the insects. In a previous study, using species of noctuid stem borers with different diet breadths, namely the polyphagous Sesamia nonagrioides, the oligophagous Busseola fusca and monophagous Busseola nairobica, it was shown that in S. nonagrioides, one generation was enough to induce a preference for vanillin in the resulting gravid females, whereas even two generations failed to induce a response in adults of Busseola spp. In this study, we checked whether a higher number of generations of exposure to a vanillin-enriched medium could induce a significant olfactory preference for this medium in the species $B$. fusca and $B$. nairobica, which have narrower host-plant utilization ranges than $S$. nonagrioides. Larvae were reared to the adult stage on an artificial diet enriched with vanillin for periods of from 2 to 7 or 8 generations, followed by two-choice tests on gravid females using a Y-tube olfactometer. The results showed different responses according to the species: for the oligophagous $B$. fusca, there was no significant effect of the conditioning, while a significant preference for the odours emitted by this new vanillin-enriched diet was recorded for the polyphagous $S$. nonagrioides and monophagous $B$. nairobica, but after different numbers of generations. In conclusion, different diet breadths seem to be associated with different levels of plasticity in the odour preference of adults. The implication of this result for insects' adaptability in a changing landscape is discussed.
\end{abstract}

\section{INTRODUCTION}

In phytophagous insects, adaptations to a new host-plant, changes in host-plant preference, host shifts, host expansion and host specialization, can be the consequence of e.g. changes in land use, domestication of plants for cultivation and introduction of new crop plants (Forbes et al., 2017). For example, in noctuid stem borer moths, it is hypothesized that Busseola fusca (Fuller) (Lepidoptera: Noctuidae) switched from wild to domesticated sorghum during the process of sorghum domestication and switched also to maize when this crop was introduced into Africa where it became a serious pest of maize (Khan et al., 2000; Haile \& Hofvsang, 2002; Sezonlin et al., 2006; Calatayud et al., 2014a). Similarly, Sesamia nonagrioides Lefebvre (Lepidoptera: Noctuidae) originally fed on wild bulrush (Typhaceae) in Africa. It migrated to Mediterranean Europe and is now a pest of maize in both Africa and Europe (Moyal et al., 2011). These examples illustrate changes in host-plant use by insects that are now important crop pests.
Many factors can induce changes in host-plant use; among them insects' plasticity and experience enhance an insect's adaptability to new host plants in a changing landscape (Miller \& Strickler, 1984; Courtney et al., 1989; Craig et al., 2001; Tremmel \& Müller, 2014).

An insect's plasticity is mainly associated with its degree of host-plant specialization. Higher plasticity (i.e. lower constraints on changes in host-plant use and easier adaptation to a new host plant) occurs in polyphagous rather than specialist insects (Bernays, 2001; Pentzold et al., 2014). When perceiving a plant at a distance, olfaction plays a crucial role in insects, in which plant volatile organic compounds (VOCs) constitute an important guidance system for host plant selection and recognition of food or oviposition sites (Bruce et al., 2005). The lower plasticity in specialist insect can be, in part, explained by the fact that they seem to be more sensitive to particular host VOCs or to characteristic mixtures of VOCs than generalists (Bernays, 2001). Nevertheless, this sensitivity to particular VOCs 
can be modified by an insect's experience, particularly larval experience or larval conditioning (Moreau et al., 2008; Anderson et al., 2013; Proffit et al., 2015; Petit et al., 2017). However, such modification may require several generations, depending on the strength of selection and the degree of specialization of the insects (e.g. Videla et al., 2010; Kühnle \& Müller, 2011; Okoth et al., 2014).

Using three species of insects with different degrees of specialization, Petit et al. (2015) show that one generation of larval exposure to a vanillin-enriched medium is sufficient to induce an olfactory preference for the odours of this medium in adult female $S$. nonagrioides; by contrast, no olfactory induction is recorded for the specialized species B. fusca and Busseola nairobica Le Ru (Lepidoptera: Noctuidae). It was therefore hypothesized that modulation of olfactory preference for a new olfactory cue depends on the degree of specialization of these insects; thereby, polyphagous species adapt faster to a new diet than more specialized species. Therefore, the low degree of polyphagy may be a genetic constraint to the adaptation to a new food. In this study, we checked whether a longer exposure to a vanillin-enriched medium could induce a significant olfactory preference for this medium in both the oligophagous, $B$. fusca, and monophagous B. nairobica species as is recorded for the polyphagous species, $S$. nonagrioides in a previous study (Petit et al., 2015).

\section{MATERIALS AND METHODS}

\section{Insects}

Busseola nairobica, a new species recently described by Félix et al. (2013), is the most specialized species included in this study and feeds mostly on the broadleaved panicum (Panicum deustum) (Le Ru et al., 2006a, b; Ong' amo et al., 2006; Ong'amo, 2009); B. fusca is an oligophagous species found on nine species of plants belonging to the Poaceae, including maize and Sorghum spp. (Le Ru et al., 2006a; Ndemah et al., 2007; Moolman et al., 2014) and $S$. nonagrioides is polyphagous and found on more than 30 species of plants belonging to Poaceae, Cyperaceae and Typhaceae (Le Ru et al., 2006a, b; Ong'amo et al., 2006).

Larvae of $B$. nairobica were collected from $P$. deustum in the Ngong forest (Nairobi, Kenya), those of $B$. fusca from maize plants in Gilgil and Mahi-Mahiu (Rift Valley, Kenya) and those of $S$. nonagrioides from Typha domingensis in Makindu (Eastern Kenya). Under artificial conditions $\left(26 \pm 1^{\circ} \mathrm{C}, 50-60 \% \mathrm{RH}\right)$, the developmental time from egg to adult emergence lasts about 90 days, 60 days and 52 days for B. nairobica, B. fusca and S. nonagrioides, respectively (C. Petit, pers. observ.).

Colonies of each species were reared on an artificial diet (Onyango \& Ochieng'-Odero, 1994) for more than 10 generations under laboratory conditions $\left(26 \pm 1^{\circ} \mathrm{C}\right.$ and $\left.50-60 \% \mathrm{RH}\right)$ before being used in the experiments. For female egg laying, artificial substrates consisting of rectangular wax papers $(15 \mathrm{~cm} \times 6 \mathrm{~cm})$ rolled helicoidally from top to bottom to form a cylindrical surrogate stem (Khan \& Saxena, 1997) were used.

\section{Experimental procedures}

The same experimental procedures as described in Petit et al. (2015) were used. Briefly, the insects were subjected to different conditions using an artificial diet enriched with vanillin (= vanillin diet), a compound not present in their natural hosts and habitat, at concentrations that have no detrimental effect on larval survival or growth (Petit et al., 2015), i.e. $1 \mathrm{~g} / \mathrm{l}$ for $B$. fusca and $S$. nonagrioides, and $0.5 \mathrm{~g} / 1$ for $B$. nairobica. Because of its longer larval development time, $B$. nairobica was reared for 2 to 7 generations while $S$. nonagrioides and $B$. fusca were reared from 2 to 8 generations on either a vanillin or control diet. Adult females never exposed to vanillin are referred hereinafter as "control" females (V0 females). Female adults that were reared continuously on a vanillin diet were tested after 2, 5, 7 or 8 generations (labelled respectively V2, V5, V7 or V8 females).

To prevent the risk of odour contamination, the rearing of insects on the vanillin and control diets was done in two separate rooms under a photoperiod of $12 \mathrm{~L}: 12 \mathrm{D}$, at $26 \pm 1{ }^{\circ} \mathrm{C}$ and $50-60 \%$ RH.

\section{Olfactometer tests}

Olfactometer tests on mated females (i.e. 2 days old females) of $S$. nonagrioides, B. fusca and B. nairobica subjected to the aforementioned conditions were performed 2-4 h after onset of the scotophase, which corresponds to the period of oviposition for

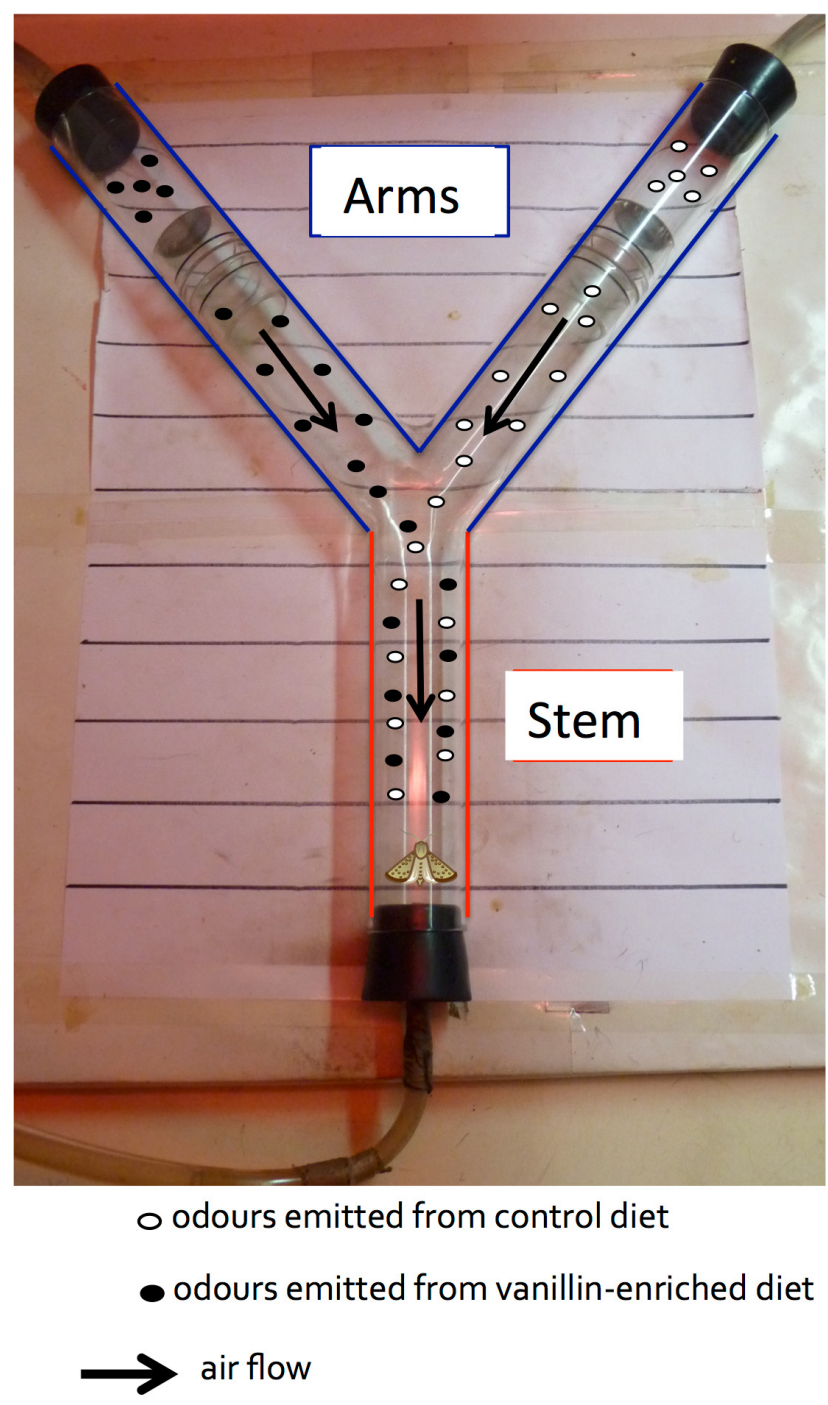

Fig. 1. The Y-tube olfactometer used by Petit et al. (2015). Briefly, the upper end of each arm of the Y-tube is connected to a single container or chamber with either of the two diets (part not visible in the figure). Airflow after being cleaned through activated charcoal and after passing through the containers with the diets flows at the same speed through each arm (in blue) of the olfactometer. A single female is placed into the open end of the stem (in red) of the olfactometer and left to choose between the odours emitted from the diet placed in each chamber and flowing through each arm. 
A Sesamia nonagrioides - polyphagous

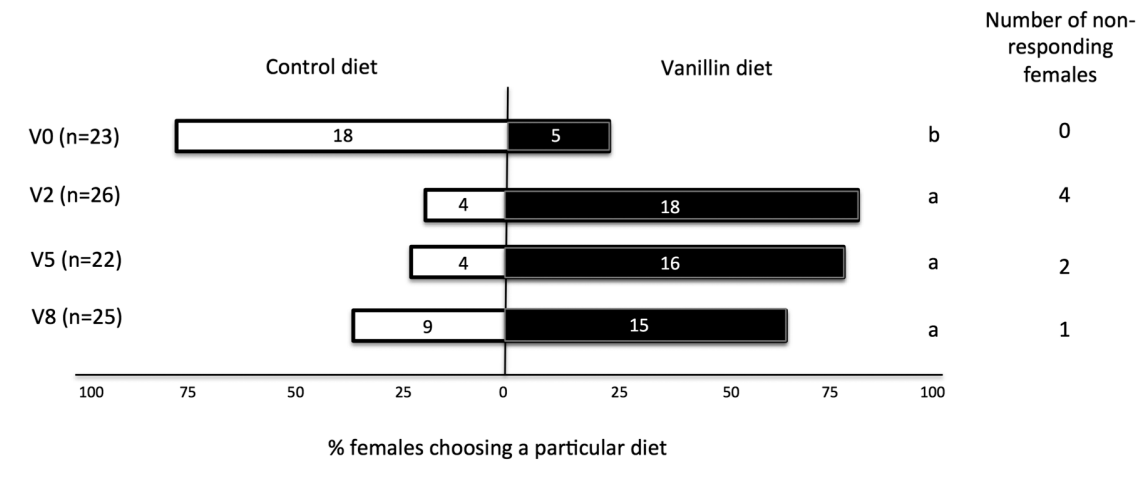

B Busseola fusca - oligophagous

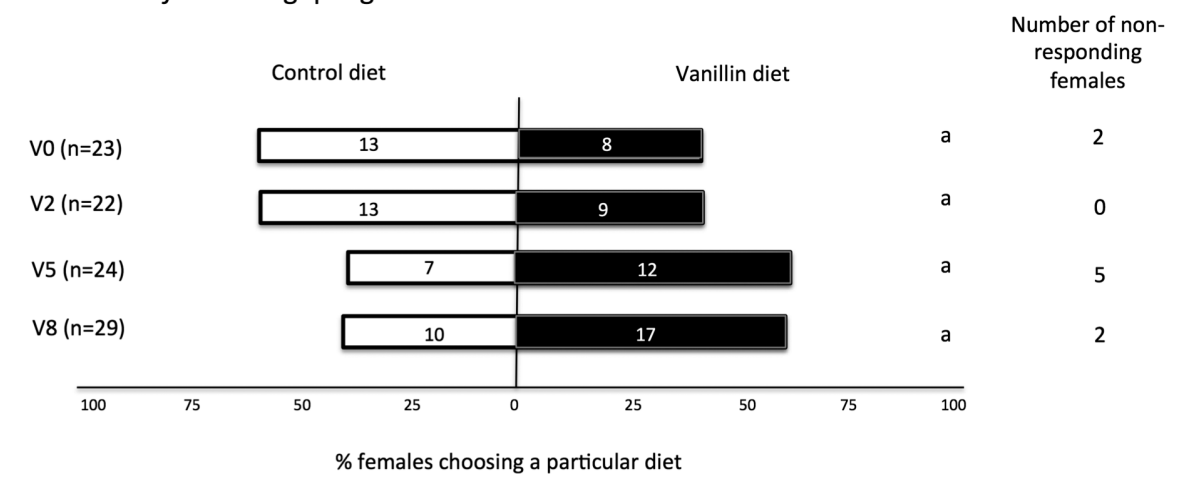

C Busseola nairobica-monophagous

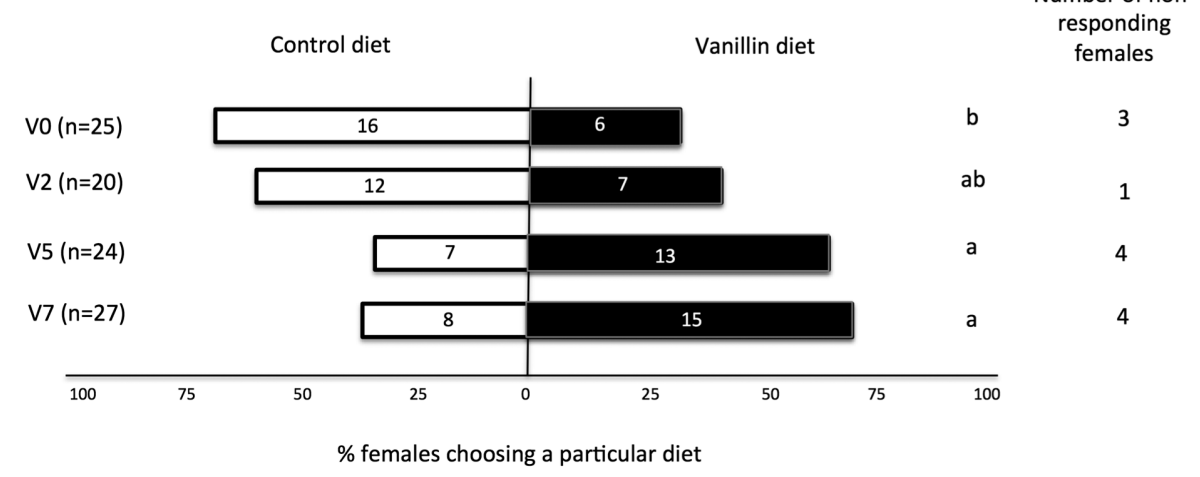

Fig. 2. Response of mated females to odours of vanillin and control diets in a Y-tube olfactometer after different periods conditioning, V0, V2, V5 and V7 or V8 (V0 insects not exposed to vanillin; V2, V5, V7 or V8 insects reared continuously on vanillin diet for 2, 5, 7 or 8 generations, respectively). (A) Sesamia nonagrioides - polyphagous, (B) Busseola fusca - oligophagous and (C) Busseola nairobica - monophagous. Between parentheses, the total number $n$ of mated females tested. The number of mated females making a choice is indicated in each bar. The $\mathrm{X}$ axis is the percentage of females choosing either the control or vanillin diet. Bars with different letters indicate significant differences at $5 \%$ level according to multiple comparisons in Chi-square tests using the Marascuilo's procedure.

each species (P.-A. Calatayud, pers. observ.). Similarly to Petit et al. (2015), a Y-tube olfactometer of Ngi-Song et al. (1996), which has been shown to be useful for demonstrating differences in attractiveness to odours in moths (Calatayud et al., 2014b), was used (length of stem: $18 \mathrm{~cm}$; length of each arm: $34 \mathrm{~cm}$; diameter: $4 \mathrm{~cm}$ ) (Fig. 1). Containers with either diet type were connected via tubing to each arm of the Y-tube. After passing through activated charcoal, clean air was drawn into the system over the sample through the arms of the olfactometer (Fig. 1). The airflow was set at $15 \mathrm{~cm} \mathrm{~s}^{-1}$ per arm and measured by flow metres connected between the chambers and the activated charcoal. For 30 mins prior to each test, air was left flowing through the olfactometer to check that it was the same in the two chambers contain- ing diet treatments and the Y-tube stem. The Y-tube experiments were carried out under dark conditions at $25 \pm 1{ }^{\circ} \mathrm{C}$ and $50-60 \%$ $\mathrm{RH}$, using a red light to allow observations. Gravid females were released individually into the stem of the Y- tube and allowed 10 min to choose between the odour of the control diet (sample of $3 \mathrm{~cm}^{3}$ ) and vanillin diet (sample of $3 \mathrm{~cm}^{3}$ ). The choice was validated when the insect moved $5 \mathrm{~cm}$ from the intersection into one arm and remained there for more than $20 \mathrm{~s}$. Those that made no choice were also recorded. After every five insects, the odour source connections to the chambers were reversed to minimise any locational bias and the chambers as well as the Y-tube were cleaned thoroughly with distilled water. For each conditioning 
procedure, the percentage of insects that chose each of the two odours was calculated.

\section{Statistical analysis}

For each species, the recorded frequencies of female orientation towards control diet and vanillin-enriched diet were compared by conducting multiple comparisons in Chi-square tests (Marascuilo's procedure) (Marascuilo, 1966). Statistical analyses were done in $\mathrm{R}$ version 3.3.1 (R Core Team, 2016).

\section{RESULTS}

Females of $S$. nonagrioides continuously exposed to the vanillin diet (V2, V5 and V8) significantly preferred the odour of this diet, whereas the control females (V0) still preferred the odour of the control diet (Fig. 2A). This induction of orientation preference towards odours of vanillin diet was apparent after two generations (V2) of exposure.

For $B$. fusca females, there was no significant effect of the conditioning, as well as no significant initial preference for the odour of the control diet (Fig. 2B).

Significant effects of the conditioning were recorded for B. nairobica after 5 generations (V5) of exposure, which is when a significant induction of preference for the vanillin diet was first recorded (Fig. 2C).

\section{DISCUSSION}

Our study illustrates that an induction of an olfactory preference for vanillin in adult females after a prolonged larval experience correlated with the host plant diet breadth of the species.

Although these results cannot be generalized between generalists and specialists, the present findings illustrate a faster phenotypic plasticity for new olfactory cues in a polyphagous compared to a specialist insect indicating a faster adaptation to a changing environment. For S. nonagrioides this plasticity towards vanillin-enriched diet occurred after one generation (Petit et al., 2015). This fast phenotypic plasticity is recorded in various generalist insects (e.g. Anderson \& Anton, 2014; Austel et al., 2014; Proffit et al., 2015). This phenomenon may have a considerable effect on agriculture. This phenotypic plasticity facilitates the establishment of insect populations on a new host plant and thus in a new environment (Brown et al., 1995; Agosta, 2006) and explains habitat shift [e.g. from wild to cultivated habitats or from Africa to Mediterranean Europe of S. nonagrioides (Moyal et al., 2011)].

In the present experiment, the increased response to vanillin-enriched diet occurred not only in the polyphagous species, $S$. nonagrioides, but also in the specialist $B$. nairobica though it took more time. As showed by Petit et al. (2015) for S. nonagrioides, this induction of preference for a new olfactory cue is the result of the combination of parent's experience and self-experience via a transfer of information from adults to offspring. This is also reported for other species of insect (Barron, 2001; Moreau et al., 2008; Anderson et al., 2013; Proffit et al., 2015; Petit et al., 2017). Thus, this phenomenon might also occur in specialist species but after a prolonged period of exposure to a new olfactory cue suggesting that B. nairobica has the capacity to switch from e.g. wild to cultivated hosts. A closely related species, namely $B$. segeta, which feeds on Pennisetum purpureum (Poaceae), has already been recorded from maize (Calatayud et al., 2014c).

No increase in the response to vanillin-enriched diet was recorded for $B$. fusca, which is less specialized than $B$. nairobica. It is probable that $B$. fusca is not as plastic in its ability to respond. However, Calatayud et al. (2008) comparing laboratory reared with wild specimens, show that $B$. fusca exhibits phenotypic changes when reared for two generations on an artificial diet (Onyango \& Ochieng'Odero, 1994). In addition, Petit et al. (2015) using electroantennography (EAG) show that $B$. fusca as well as $S$. nonogrioides and $B$. nairobica possess sensory receptors for vanillin. This indicates that the absence of induction of olfactory preference for vanillin in B. fusca in our study cannot be explained by an inability to smell vanillin but rather to a specific natural history/evolutionary background that might constrain the ability of $B$. fusca to show a preference for vanillin as compared to the other species used in this study.

In conclusion, our behaviour-based study indicates that the plasticity in the odour preference of adults is related to differences in their diet breadths with the number of generations of exposure to an odour necessary for induction dependent on the diet breadth characteristics of the insect.

ACKNOWLEDGEMENTS. Thanks are given to F. Schulthess for critically reading the manuscript and correcting the English. This work was supported by funding from the French ANR (Agence Nationale de la Recherche) (Adaptanthrop project ANR-09PEXT-009) and the French Ministry of Foreign Affairs (VCI grant) (Chargé de Volontaire International $\mathrm{N}^{\circ} 04036500$ ).

\section{REFERENCES}

Agosta S.J. 2006: On ecological fitting, plant-insect associations, herbivore host shifts, and host plant selection. - Oikos 114: 556-565.

ANDERSON P. \& ANTON S. 2014: Experience-based modulation of behavioural responses to plant volatiles and other sensory cues in insect herbivores. - Plant Cell Environ. 37: 1826-1835.

Anderson P., Sadek M.M., Larsson M., Hansson B.S. \& Thöming G. 2013: Larval host plant experience modulates both mate finding and oviposition choice in a moth. - Anim. Behav. 85: 1169-1175.

Austel N., Bü̈rkman C., Hilker M. \& Meiners T. 2014: Phenotypic plasticity in host plant preference of the willow leaf beetle Phratora vulgatissima: the impact of experience made by adults. - Agr. Forest Entomol. 16: 417-425.

BARRon A.B. 2001: The life and death of Hopkins' host-selection principle. - J. Insect Behav. 14: 725-737.

BERNAYS E.A. 2001: Neural limitations in phytophagous insects: implications for diet breadth and evolution of host affiliation. - Annu. Rev. Entomol. 46: 703-727.

Brown J.M., Abrahamson W.G., Packer R.A. \& Way P.A. 1995: The role of natural-enemy escape in a gallmaker host-plant shift. - Oecologia 104: 52-60.

Bruce T.J., Wadhams L.J. \& Woodcock C.M. 2005: Insect host location: a volatile situation. - Trends Plant Sci. 10: 269-274.

Calatayud P.-A., Juma G., Nuagi P.G.N., Faure N., Calatayud S., Dupas S., Le Ru B., Magoma G., Silvain J.-F. \& Frérot 
B. 2008: Differences in mate acceptance and host plant recognition between wild and laboratory-reared Busseola fusca (Fuller). - J. Appl. Entomol. 132: 255-264.

Calatayud P.-A., Le Ru B., Van Den Berg J. \& Schulthess F. 2014a: Ecology of the African maize stalk borer, Busseola fusca (Lepidoptera: Noctuidae) with special reference to insect-plant interactions. - Insects 5: 539-563.

Calatayud P.-A., Ahuya P. \& Le Ru B. 2014b: Importance of the experimental setup in research on attractiveness of odours in moths: an example with Busseola fusca. - Entomol. Exp. Appl. 152: 72-76.

Calatayud P.-A., Okuku G., Musyoka B., Khadioli N., Ong'amo G. \& LE RU B. 2014c: Busseola segeta, a potential new pest of maize in Western Kenya. - Entomol. Ornithol. Herpetol. 3: 132, 2 pp.

Courtney S.P., Chen G.K. \& Gardner A. 1989: A general model for individual host selection. - Oikos 55: 55-65.

Craig T.P, Horner J.D. \& Itami J.K. 2001: Genetics, experience, and host-plant preference in Eurosta solidaginis: Implications for host shifts and speciation. - Evolution 55: 773-782.

Félix A.-E., Calatayud P.-A., Le Ru B., Capdevielle-Dulac C., Ong'Amo G., Silvain J.-F. \& Frérot B. 2013: To be or not to be a species: use of reproductive isolation experiments and genetic analysis to clarify the taxonomic status of two Busseola (Lepidoptera: Noctuidae) species in Kenya. - Ann. Soc. Entomol. Fr. 49: 345-354.

Forbes A.A., Devine S.N., Hippee A.C., Tvedte E.S., Ward A.K., WIDMAYER H.A. \& WILSON C.J. 2017: Revisiting the particular role of host shifts in initiating insect speciation. - Evolution 71: $1126-1137$.

Haile A. \& Hofsvang T. 2002: Host plant preference of the stem borer Busseola fusca (Fuller) (Lepidoptera: Noctuidae). Crop Prot. 21: 227-233.

KHAN Z.R. \& SAXENA R.C. 1997: Use of a surrogate stem for eliciting ovipositional response of Busseola fusca (Lepidoptera: Noctuidae). - J. Econ. Entomol. 90: 1426-1429.

Khan Z.R., Pickett J.A., van den Berg J., Wadhams L.J. \& Woodcock C.M. 2000: Exploiting chemical ecology and species diversity: stem borer and striga control for maize and sorghum in Africa. - Pest Manag. Sci. 56: 957-962.

KüHNLE A. \& MÜlLeR C. 2011: Responses of an oligophagous beetle species to rearing for several generations on alternative host-plant species. - Ecol. Entomol. 36: 125-134.

Le Ru B.P., Ong'amo G., Moyal P., Muchugu E., Ngala L., Musyoka B., Abdullah Z., Matama-Kauma T., Lada V.Y., Pallangyo B., Omwega C.O., Schulthess F., Calatayud P.-A. \& SiLvaIn J.-F. 2006a: Geographic distribution and host plant ranges of East African noctuid stem borers. - Ann. Soc. Entomol. Fr. 42: 353-361.

Le Ru B.P., Ong'amo G.O., Moyal P., Ngala L., Musyoka B., Abdullah Z., Cugala D., Defabachew B., Haile T.A., Kauma Matama T., Lada V.Y., Negassi B., Pallangyo B., Ravolonandrianina J., Sidumo A., Omwega C.O., Schulthess F., CALATAYUd P.-A. \& Silvain J.-F. 2006b: Diversity of lepidopteran stem borers on monocotyledonous plants in eastern Africa and the islands of Madagascar and Zanzibar revisited. - Bull. Entomol. Res. 96: 555-563.

Marascuilo L. 1966: Large-sample multiple comparisons. Psychol. Bull. 65: 289-299.

Miller J.R. \& Strickler K.L. 1984: Finding and accepting host plants. In Bell W.J. \& Cardé R.T. (eds): Chemical Ecology of Insects. Sinauer Associates, Sunderland, pp. 127-150.

Moolman J., Van den Berg J., Conlong D., Cugala D., Siebert S. \& LE Ru B. 2014: Species diversity and distribution of lepidopteran stem borers in South Africa and Mozambique. - $J$. Appl. Entomol. 138: 52-66.
Moreau J., Rahme J., Benrey B. \& Thiéry D. 2008: Larval host plant origin modifies the adult oviposition preference of the female European grapevine moth Lobesia botrana. - Naturwissenschaften 95: 317-324.

Moyal P., Tokro P., Bayram A., Savopoulou-Soultani M., Conti E., Eizaguirre M., Le Ru B., Avand-Faghih A., Frérot B. \& ANDREAdis S. 2011: Origin and taxonomic status of the Palearctic population of the stem borer Sesamia nonagrioides (Lefèbvre) (Lepidoptera: Noctuidae). — Biol. J. Linn. Soc. 103: 904-922.

Ngi-Song A.J., Overholt W.A., Nuagi P.G.N., Dicke M., Ayertey J.N. \& LWANDE W. 1996: Volatile infochemicals used in host an host habitat location by Cotesia flavipes Cameron and Cotesia sesamiae (Cameron) (Hymenoptera: Braconidae), larval parasitoids of stemborers on graminae. - J. Chem. Ecol. 22: 307-323.

Ndemah R., Schulthess F., Le Rü B. \& Bame I. 2007: Lepidopteran cereal stemborers and associated natural enemies on maize and wild grass hosts in Cameroon. - J. Appl. Entomol. 131: 658-668.

Окотн C.A., Deng A.L., Tabu I.M., Akutse K.S. \& Fiaboe K.K.M. 2014: Effect of host plant on feeding, biological and morphological parameters of Liriomyza huidobrensis Blanchard (Diptera: Agromyzidae ). - Afr. Entomol. 22: 577-588.

Ong'Amo G.O. 2009: Diversity, Ecology and Population Dynamics of Lepidopteran Stem Borers in Kenya. PhD Thesis, Kenyatta University, Nairobi, $126 \mathrm{pp}$.

Ong’amo G.O., Le Ru B.P., Dupas S., Moyal P., Calatayud P.-A. \& Silvain J.-F. 2006: Distribution, pest status and agro-climatic preferences of lepidopteran stem borers of maize in Kenya. Ann. Soc. Entomol. Fr. 42: 171-177.

OnYANGo F.O. \& OChIENG'-Odero J.P.R. 1994: Continuous rearing of the maize stem borer Busseola fusca on an artificial diet. - Entomol. Exp. Appl. 73: 139-144.

Pentzold S., Zagrobelny M., Rook F. \& BaK S. 2014: How insects overcome two-component plant chemical defence: plant B-glucosidases as the main target for herbivore adaptation. Biol. Rev. Camb. Philos. Soc. 89: 531-551.

Petit C., Le Ru B., Dupas S., Frérot B., Ahuya P., KaiserArnauld L., Harry M. \& Calatayud P.-A. 2015: Influence of dietary experience on the induction of preference of adult moths and larvae for a new olfactory cue. - PLOS ONE 10(8): e0136169, 11 pp.

Petit C., Dupas S., Thiéry D., Capdevielle-Dulac C., Le Ru B., HarRy M. \& CAlatayud P.-A. 2017: Do the mechanisms modulating host preference in holometabolous phytophagous insects depend on their host plant specialization? - J. Pest Sci. 90: 797-805.

Proffit M., Khallaf M.A., Carrasco D., Larsson M.C. \& ANDERSON P. 2015: 'Do you remember the first time?' Host plant preference in a moth is modulated by experiences during larval feeding and adult mating. - Ecol. Lett. 18: 365-374.

Sezonlin M., Dupas S., Le Ru B., Le Gall P., Moyal P., Calatayud P.-A., Giffard I., Faure N. \& Silvain J.-F. 2006: Phylogeography and population genetics of the maize stalk borer Busseola fusca (Lepidoptera, Noctuidae) in sub-Saharan Africa. - Mol. Ecol. 15: 407-420.

Tremmel M. \& Müller C. 2014: Diet dependent experience and physiological state shape the behavior of a generalist herbivore. - Physiol. Behav. 129: 95-103.

Videla M., Valladares G. \& Salvo A. 2010: Differential effects of experience on feeding and ovipositing preferences of a polyphagous leafminer. - Entomol. Exp. Appl. 137: 184-192.

Received October 2, 2017; revised and accepted February 22, 2018 Published online March 6, 2018 